\title{
Effect of roughness formulation on the performance of a coupled wave, hydrodynamic, and sediment transport model
}

\author{
Neil K. Ganju *, Christopher R. Sherwood \\ U.S. Geological Survey, Coastal and Marine Geology, 384 Woods Hole Road, Woods Hole, MA 02543, USA
}

\section{A R T I C L E I N F O}

\section{Article history:}

Received 13 October 2009

Received in revised form 19 March 2010

Accepted 22 March 2010

Available online 27 March 2010

\section{Keywords:}

Sediment transport

Roughness

Bottom-boundary layer

Model skill

\begin{abstract}
A B S T R A C T
A variety of algorithms are available for parameterizing the hydrodynamic bottom roughness associated with grain size, saltation, bedforms, and wave-current interaction in coastal ocean models. These parameterizations give rise to spatially and temporally variable bottom-drag coefficients that ostensibly provide better representations of physical processes than uniform and constant coefficients. However, few studies have been performed to determine whether improved representation of these variable bottom roughness components translates into measurable improvements in model skill. We test the hypothesis that improved representation of variable bottom roughness improves performance with respect to nearbed circulation, bottom stresses, or turbulence dissipation. The inner shelf south of Martha's Vineyard, Massachusetts, is the site of sorted grain-size features which exhibit sharp alongshore variations in grain size and ripple geometry over gentle bathymetric relief; this area provides a suitable testing ground for roughness parameterizations. We first establish the skill of a nested regional model for currents, waves, stresses, and turbulent quantities using a uniform and constant roughness; we then gauge model skill with various parameterization of roughness, which account for the influence of the wave-boundary layer, grain size, saltation, and rippled bedforms. We find that commonly used representations of rippleinduced roughness, when combined with a wave-current interaction routine, do not significantly improve skill for circulation, and significantly decrease skill with respect to stresses and turbulence dissipation. Ripple orientation with respect to dominant currents and ripple shape may be responsible for complicating a straightforward estimate of the roughness contribution from ripples. In addition, sediment-induced stratification may be responsible for lower stresses than predicted by the wave-current interaction model.
\end{abstract}

Published by Elsevier Ltd.

\section{Introduction}

\subsection{Hydrodynamic bottom roughness in coastal ocean models}

Bottom stress is a first-order term in the momentum equations that describe coastal circulation and sediment transport, and an essential component of numerical models that represent these processes. It is also important in the generation of near-bed turbulence and subsequently governs mixing near the bed and the dissipation of surface gravity waves. Bottom stress $\tau_{0}$ in coastal ocean models is typically parameterized with a linear or quadratic relationship between a drag coefficient $C_{d}$ and flow velocity $U$ at a specific elevation $z$ above the bottom. The quadratic formulation is

$\tau_{0}=\rho C_{D} U|U|$

where $\rho$ is fluid density. This is consistent with a logarithmic profile defined by

\footnotetext{
* Corresponding author. Tel.: +1 5084572252.

E-mail address: nganju@usgs.gov (N.K. Ganju).
}

$|U|=\frac{\sqrt{\left|\tau_{0}\right| / \rho}}{\kappa} \ln \frac{z}{z_{0}}$

where $z_{0}$ is the hydrodynamic bottom roughness (simply "roughness" hereafter) length and $\kappa$ is von Kármán's constant (approximately 0.41 ). This is strictly true only where the flow is unstratified, fully turbulent, steady, and horizontally uniform. In addition, the velocities are assumed to represent measured or modeled flow (1) within the constant-stress portion of the bottom boundary; (2) well above the viscous sublayer; and/or (3) above the tops of roughness elements that contribute to the bottom drag.

Despite these assumptions, logarithmic profiles are a robust and useful approximation to the near-bottom flow even as the theoretically necessary conditions are relaxed. Therefore, many models formulate bottom stress in terms of a roughness $z_{0}$, or a Nikuradse roughness length $k_{s}=30 z_{0}$ (Nikuradse, 1933).

Roughness lengths are used in coastal ocean models to parameterize drag associated with grain roughness $z_{0 N}$, the effect of saltating grains during sediment transport $z_{0 S T}$, and small-scale bottom topography (ripples and biogenic features) $z_{0 B F}$. These 
roughness lengths, as physical distances, are assumed to be additive (Warner et al., 2008), so bottom-boundary layer calculations use

$z_{0}=\max \left[z_{0 N}+z_{0 S T}+z_{0 B F}, \quad z_{0 M I N}\right]$

where $z_{0 M I N}$ is a lower limit representing viscous drag, with a typical value of $5 \times 10^{-5} \mathrm{~m}$ (Soulsby, 1997). In some cases, one term may dominant the roughness length, depending on physical forcing and bed composition.

Roughness lengths associated with grain roughness $z_{0 N}$, sediment transport $z_{0 S T}$, and bedform roughness length (ripples) $z_{0 B F}$ are estimated as

$z_{0 N}=2.5 D_{50} / 30$

$z_{0 S T}=\alpha D_{50} \cdot a_{1} \frac{T_{*}}{1+a_{2} T_{*}}$

$z_{0 B F}=a_{r} \eta_{r}^{2} / \lambda_{r}$

where $D_{50}$ is the median grain size (in meters), $\alpha=0.056, a_{1}=0.068$, $a_{2}=0.024 \ln \left(100 D_{50}^{2}\right)+0.0709 \ln \left(100 D_{50}\right), T^{*}$ is the ratio of applied shear stress to the critical erosion shear stress (Wiberg and Rubin, 1989), $\eta_{r}$ is ripple height, $\lambda_{r}$ is ripple wavelength, and $a_{r}$ is a coefficient that may range from 0.3 to 3 for current-generated ripples (Soulsby, 1997). Grant and Madsen (1982) proposed $a_{r}=0.923$; Raudkivi (1988) used 0.533; and Nielsen (1992) suggested $a_{r}=0.267$ for wave-generated ripples.

Roughness lengths are also used to parameterize the drag created by near-bottom wave-induced turbulence (Grant and Madsen, 1979; Signell et al., 1990). Wave-current interaction models predict an apparent roughness length $z_{0 a p p}$ that is generally larger than the inner $z_{0}$ that represents the drag imposed on wave motions by bottom sediment, saltation, or small-scale bed topography. Conversely, near-bed stratification can reduce the bottom stress and reduce the roughness length. Therefore the computation of stresses in a mixed wave-current environment involves specification of multiple physical roughness contributions and the interaction of those contributions with a wave-current interaction model including, if relevant, the influence of stratification. In this study we refer to the "inner roughness" as the physical roughness perceived by the inner wave-boundary layer (calculated using Eq. (3)), and the "apparent roughness" as the roughness perceived by the outer current boundary layer. The latter is typically calculated using a wave-current interaction model such as Madsen's (1994).

\subsection{Effects of roughness parameterization in regional ocean models}

The initial spatial distribution of roughness length due to grains and small-scale topography is poorly understood in most cases, due to the inherent difficulty of sampling and/or temporally varying conditions. Modern geophysical techniques allow for nonintrusive estimation of sediment grain size, type, and bedform dimensions. From these, a reasonable initial condition can be specified for roughness length. Sediment transport models, in combination with time-dependent ripple models, calculate evolving ripple dimensions, based on grain size, bottom orbital velocities, and near-bed flow velocity.

It may be imperative to incorporate these types of data into regional models, given the evidence for large spatial variability in sediment grain size and bedform type throughout the continental shelf (Goff et al., 2008). However, few studies have quantified the influence of spatially and temporally varying roughness on model skill. Davies and Lawrence (1995), modeling the Irish Sea, found small changes in modeled velocity magnitude when spatial variations in roughness were considered, though changes in residual patterns or bottom shear stress were not addressed. Nicolle and Karpytchev (2007) found improvements in tidal amplitude and phase when "frictional contrast" was implemented in a semi-enclosed basin. This frictional contrast resulted from the presence of hydrodynamically smooth mudflats over a portion of the domain. Lopes and Dias (2007) addressed the spatial variability in roughness while modeling a Portuguese lagoon, but were not able to show that incorporating this roughness improved performance. The roughness contribution of benthic organisms was considered by Seifert et al. (2009); small changes were observed with regards to modeled mean currents, though no information is given with regard to model skill. Lu and Zhang (2006) selected spatially varying bottom friction coefficients using assimilation of altimeter data, resulting in larger coefficients in shallow water. The influence of roughness is not specifically addressed in the study, though it is implied that it may be responsible for unexplained variability in the bottom friction coefficient. Storm surge modeling in the Irish Sea was improved using a wave-current interaction routine that resulted in spatially varying friction (Jones and Davies, 1998). Establishing the need for spatially and temporally variable (simply "variable" hereafter) roughness in hydrodynamic, wave, and sediment transport models requires both intensive field measurements and models that account for roughness elements.

Our goal is to implement several representations of roughness into a realistic coastal ocean model, and determine if there is a quantifiable increase in model skill for near-bed current magnitude, direction, bottom shear stress, and turbulence dissipation. These representations include a logarithmic velocity method with uniform and constant (simply "uniform" hereafter) roughness, the wave-current interaction method of Madsen (1994) with uniform inner roughness, and wave-current interaction with an inner roughness that accounts for ripple evolution.

Sorted grain-size features near the Martha's Vineyard Coastal Observatory (MVCO) may provide enhanced roughness in nearshore areas due to gradients in grain size and ripple dimensions (Goff et al., 2005), and provide a suitable case for this study. The parameterization of these features can be achieved by considering the effect of variable grain-size and ripple geometry, though it is not clear what effect this parameterization has on near-bed circulation and bottom stresses. It is also not clear whether incorporating variable roughness actually increases model skill. Intensive measurements of velocity and wave parameters over the sorted grain-size features near MVCO enable us to investigate the performance of regional models with variable roughness. We first describe the field setting and data collection, followed by a description of the numerical model, and the skill assessment methodology.

\section{Site description and field data}

\subsection{Hydrodynamic setting}

The MVCO is located on the southeast New England Shelf, $1.5 \mathrm{~km}$ offshore of the southern edge of Martha's Vineyard (Fig. 1). The MVCO consists of a shore lab, air-sea interaction tower (15 $\mathrm{m}$ isobath), and a subsurface node (12 m isobath). The $12 \mathrm{~m}$ node is located $1.5 \mathrm{~km}$ south of the shoreline, and provides continuous cabled power for oceanographic equipment. Tidal currents at MVCO are dominated by the alongshore component (approaching $0.5 \mathrm{~m} / \mathrm{s}$ at spring tide), while the cross-shore component is significantly smaller $(0.1 \mathrm{~m} / \mathrm{s})$. Tidal range is over $1 \mathrm{~m}$ during spring tides. The largest waves arrive from the south with heights exceeding $4 \mathrm{~m}$ and maximum wave periods in excess of $10 \mathrm{~s}$. During the field study described here, maximum significant wave height was $2 \mathrm{~m}$. The steeply sloping beaches and rocky coastline on the southern edge of Martha's Vineyard suggest that intertidal processes, e.g. wetting and drying, are not important to inner-shelf circulation. 


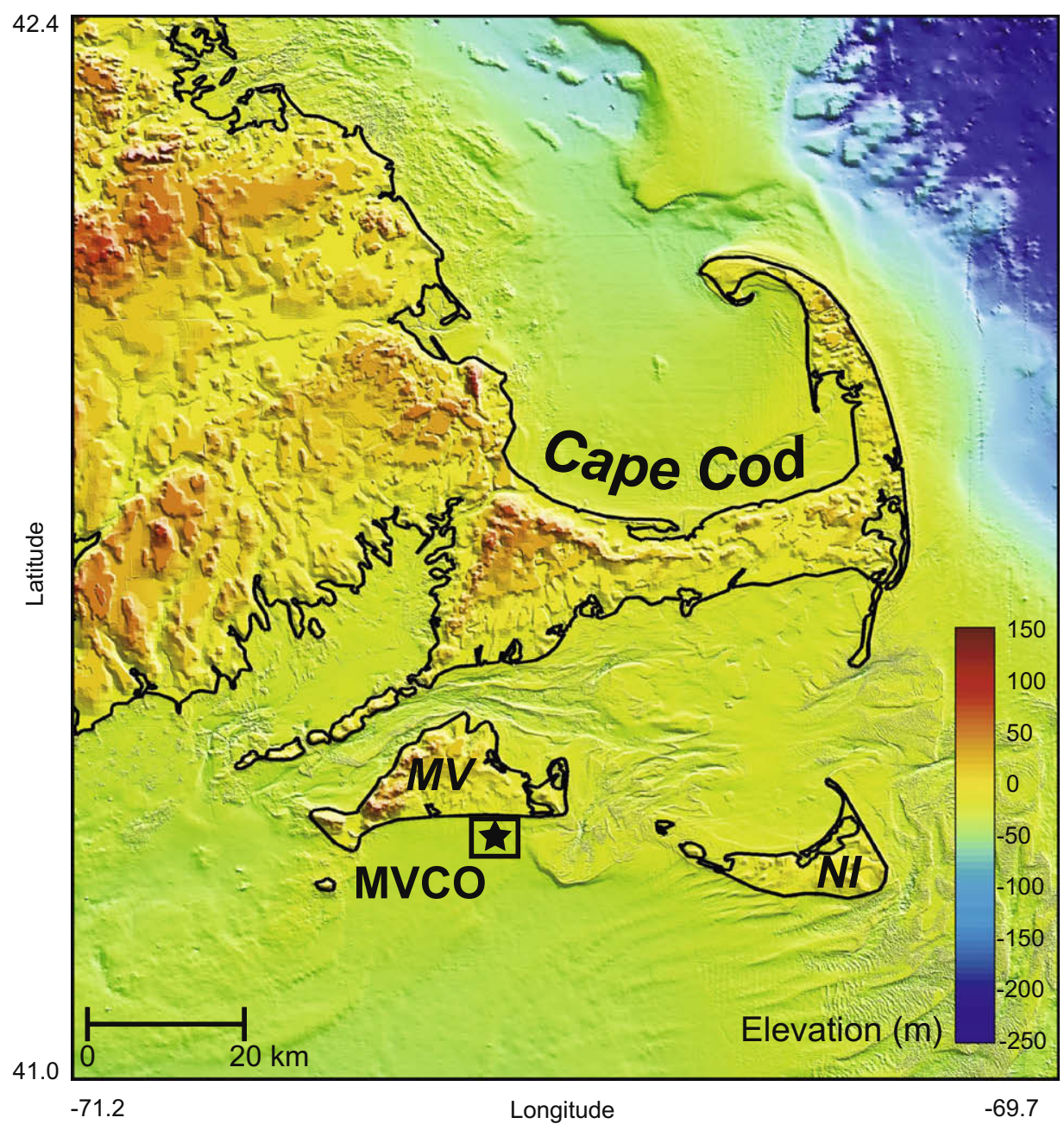

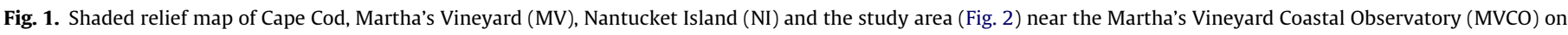
the inner New England shelf.

Hydrodynamics near the MVCO are influenced by larger regional patterns, highlighting the need for multiple nested grids and increased nearshore grid resolution. Subtidal-frequency circulation over the inner shelf of southeastern New England is characterized by predominantly westward flow, caused by geostrophic and barotropic forcing, though seasonal variability is observed due to stratification in the spring and fall (Shearman and Lentz, 2003). Tidal forcing is influenced by the Gulf of Maine (to the north) and the mid-Atlantic Bight (to the south). Offshore of the MVCO, He and Wilkin (2006) identified $\mathrm{M}_{2}$ maximum tidal amplitudes of $1 \mathrm{~m}$, depth-averaged currents approaching $1.5 \mathrm{~m} / \mathrm{s}$, and tidal residual circulation (depth-averaged) under $0.1 \mathrm{~m} / \mathrm{s}$, using a hybrid data assimilation modeling technique. Winds and waves along the northeast coast of the US are influenced by "northeasters" (Butman et al., 2008), which typically occur between the late fall and spring. These storm systems can produce winds exceeding $20 \mathrm{~m} / \mathrm{s}$ and significant wave heights over $7 \mathrm{~m}$ on the inner shelf (National Buoy Data Center, www.nbdc.noaa.gov; buoy 44018; Fig. 3).

\subsection{Sorted grain-size features}

Geophysical surveys revealed the presence of sorted grain-size features near the MVCO (Goff et al., 2005). Sorted grain-size features are commonly associated with sandy nearshore and inner shelf regions (Cacchione et al., 1984; Murray and Thieler, 2004).
They exhibit sharp alongshore gradients in grain-size and relatively gentle bathymetric changes in the alongshore direction. Sorted grain-size features near MVCO consist of bathymetric lows with coarse $(0.5 \mathrm{~mm})$ sand and large ripples (heights of $0.10-$ $0.15 \mathrm{~m}$, wavelengths of $0.6-0.8 \mathrm{~m}$ ) and bathymetric highs with fine sand $(0.125 \mathrm{~mm})$ and small ripples (heights of $0.01 \mathrm{~m}$, wavelengths of $0.1 \mathrm{~m}$ ). The features extend from the shallowest region surveyed $(6 \mathrm{~m})$ to depths of $17 \mathrm{~m}, 3 \mathrm{~km}$ offshore, with a maximum alongshore width of less than $1 \mathrm{~km}$. Goff et al. (2005) demonstrated changes in the fine/coarse sand boundaries (tens of meters on the monthly timescale), but found little migration of the bathymetric features over the decadal timescale. The features are underlain by a coarse sand and gravel layer (Goff et al., 2005). Murray and Thieler (2004) hypothesized that these features arise through self-organization and feedback between roughness, enhanced turbulence, and winnowing of fine sediments from the bed.

\subsection{Field data}

The U.S. Geological Survey performed a bathymetry and sidescan sonar survey of the study area in August, 2007, using a 234$\mathrm{kHz}$ interferometric multibeam sonar, a dual-frequency 100/ $500 \mathrm{kHz}$ sidescan-sonar system, and real-time kinematic positioning with a differential global positioning system. The resulting 
digital elevation model had a 4-m horizontal grid resolution, an estimated horizontal accuracy of $\sim 2 \mathrm{~m}$, and vertical precision of $\sim 0.10$ m (Denny et al., 2009). This bathymetry was merged with a new $1^{\prime \prime}$ digital bathymetric grid constructed by R. Signell (pers. comm.) for the region $\left(41.0-42.4^{\circ} \mathrm{N}, 71.2-69.7^{\circ} \mathrm{W}\right)$ using all digital sounding data available from the National Geophysical Data Center (www.ngdc.noaa.gov; Fig. 1). Remaining data gaps were filled by digitizing smooth sheets from older non-digital surveys. The sounding data were adjusted from mean low water or mean lower-low water datums to mean sea level using the NOAA Vdatum model for the Gulf of Maine and merged with 1 arc-second land topography. The soundings were gridded using the Generic Mapping Tools (GMT; Wessel and Smith, 1998). The sidescan backscatter amplitudes from the August survey clearly delineate the coarse and fine patches (Fig. 2). Grain-size analyses of bottom samples collected during instrument deployment at 8, 12, and 16-m sites in September 2007 revealed that the sediment distribution within each patch was unimodal with representative sizes of $0.5 \mathrm{~mm}$ in coarse patches, and $0.125 \mathrm{~mm}$ in finer patches.
Current, wave, and stress measurements were made using a variety of instruments, at multiple depths, over both fine and coarse patches (Fig. 2; Table 1). All acoustic Doppler velocimeters (ADVs) were placed near-bed ( $<2 \mathrm{mab})$ to enable measurement of near-bed velocity and wave orbital velocity. Acoustic Doppler current profilers (ADCPs) measured at elevations beginning $\sim 3 \mathrm{~m}$ from the bottom to the surface. At sites PV1 - PV6, 68-min bursts were collected every $4 \mathrm{~h}$, while 30 -min bursts were collected every $1 \mathrm{~h}$ at all other ADV sites. ADCPs collected data every $15 \mathrm{~min}$ at the MVCO, and 6 min at the USGS site. Wave statistics were calculated from ADV data using the PUV method.

Bottom stresses were calculated at sites USGS and NODE using three methods: log-profile, inertial-dissipation (Huntley, 1988), and covariance techniques (Trowbridge, 1998; Trowbridge and Elgar, 2001). These methods produce estimates of distinct quantities (shear, dissipation, and stresses, respectively), that are related depending on conditions. However, the covariance technique is deemed the most reliable, as it is the most representative estimate of near-bottom kinematic stress (Sherwood et al., 2006).

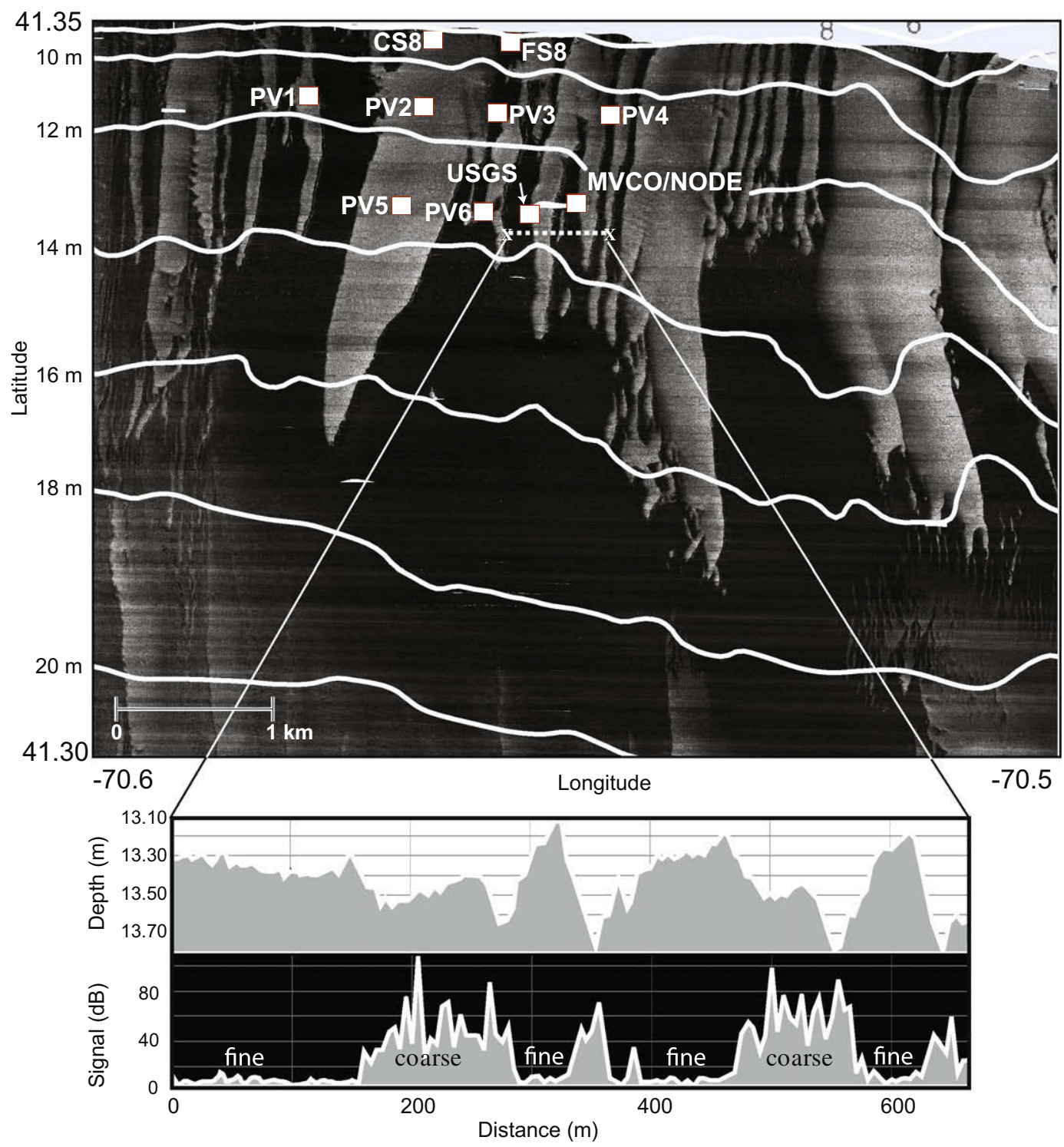

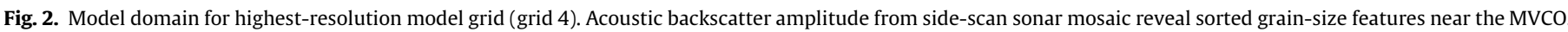

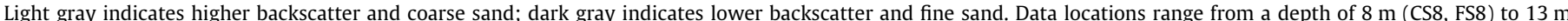


features, with fine and coarse patches. 
Table 1

Location and description of measurement sites. ADCP sensor depths indicate height of first measurement bin above bottom.

\begin{tabular}{|c|c|c|c|c|c|c|}
\hline Site ID & Lat & Lon & Sediment type & Water depth (m) & Sensor depth (mab) & Instruments \\
\hline MVCO & 41.3366 & -70.5564 & Fine & 12.0 & 3.2 & $\mathrm{ADCP}$ \\
\hline PV1 & 41.3429 & -70.5769 & Coarse & 11.1 & 1.6 & ADV \\
\hline PV2 & 41.3422 & -70.5680 & Coarse & 10.8 & 1.6 & ADV \\
\hline PV3 & 41.3418 & -70.5622 & Fine & 10.9 & 1.6 & ADV \\
\hline PV4 & 41.3416 & -70.5531 & Boundary & 11.0 & 1.6 & ADV \\
\hline PV5 & 41.3363 & -70.5698 & Coarse & 12.9 & 1.6 & ADV \\
\hline PV6 & 41.3360 & -70.5633 & Fine & 13.0 & 1.6 & ADV \\
\hline FS8 & 41.3457 & -70.5568 & Fine & 8.0 & 0.45 & ADV \\
\hline CS8 & 41.3457 & -70.5608 & Coarse & 8.0 & 0.45 & ADV \\
\hline USGS & 41.3359 & -70.5597 & Boundary & 12.5 & $0.4,3.2$ & ADV, ADCP \\
\hline NODE & 41.3366 & -70.5564 & Fine & 12.0 & 0.75 & $\operatorname{ADV}(2)$ \\
\hline
\end{tabular}

Note: ADVs used include Nortek, Sontek; ADCPs from RD Instruments.

\section{Numerical experiments}

Our approach for testing roughness parameterizations focuses on the development of a realistic model of the MVCO region. Nesting from the basin-scale down to the scale of sorted grain-size features is necessary to account for subtidal forcing and wave propagation. We evaluate general model performance, using a uniform roughness, at the multiple nest levels using water level and depth-averaged velocity at one location (MVCO), and then test whether performance for near-bed circulation, bottom shear stress, and turbulence dissipation at near-bed sites is improved by including various roughness parameterizations. Skill assessment with respect to near-bed quantities essentially amounts to a model validation process for near-bed model physics.

\subsection{Community Sediment Transport Modeling System}

We use the Community Sediment Transport Modeling System (CSTMS; Warner et al., 2008), an open-source numerical modeling system that provides for two-way coupling of the Regional Ocean Modeling System (ROMS) with SWAN, an open-source wave model (Booij et al., 1999). ROMS is a three-dimensional, free surface, terrain-following numerical model that solves finite-difference approximations of the Reynolds-averaged Navier-Stokes equations using the hydrostatic and Boussinesq assumptions (Chassignet et al., 2000; Haidvogel et al., 2000) with a split-explicit time stepping algorithm (Shchepetkin and McWilliams, 2005; Haidvogel et al., 2008). It uses a horizontal curvilinear Arakawa $C$ grid and vertical stretched terrain-following coordinates. We used the generic length-scale method to represent a two-equation $(k-\varepsilon)$ turbulence submodel in our calculations of eddy viscosity (Umlauf and Burchard, 2003; Warner et al., 2005). SWAN solves wave-averaged transport equations for wave action density (energy density divided by relative frequency) and accounts for shoaling, refraction, wind-wave generation, wave breaking, bottom dissipation, and nonlinear wave-wave interactions. Further details regarding the SWAN model are documented by Booij et al. (1999). Specific details for parameter specification, boundary conditions, and model coupling are included below.

\subsection{Bottom-boundary layer}

Bottom stresses were determined in the bottom-boundary layer routines of ROMS, which offer a range of options (Warner et al., 2008). We present three different approaches to these calculations here. In the simplest case, we specified a uniform roughness $z_{0}$ that determined bed stresses consistent with a logarithmic speed profile in the bottom computational cell. A more complex computation parameterized wave-current boundary layer processes (following Madsen, 1994) and, when waves were present, produced enhanced drag on the mean flow and increased bed stresses that were particularly important for sediment transport. At this second level of complexity, a uniform inner roughness length required as input to the wave-current calculation was specified, but the resulting apparent roughness acting on the mean flow varied with depth and wave conditions, derived from our SWAN wave model simulations. At the third and highest level of complexity, roughness calculations were fully dynamic and the inner roughness length provided to the wave-current routine accounted for local grain size, saltation (Wiberg and Rubin, 1989), and ripple height and wavelength (Eq. (6); Grant and Madsen, 1982; Raudkivi, 1988; Nielsen, 1992). These calculations do not account for more complex aspects of ripple geometry such as shape or orientation.

Ripple geometry (height, wavelength, and crest orientation) were determined using the time-dependent approach developed by Soulsby and Whitehouse (2005; hereafter SW05). The SW05 model, as we implemented it in ROMS, postulated that ripples on a mobile bed tend toward an equilibrium geometry that depends on sediment characteristics, wave conditions, current velocity, and the relative strength of waves versus mean currents. The rate at which ripple geometry evolved toward equilibrium values was determined by transport conditions and amount of disequilibria. For example, ripple heights evolved according to

$\frac{d \eta_{r}}{d t}=\frac{\beta}{T}\left(\eta_{e q}-\eta_{r}\right)$

where $\eta_{r}$ was the extant ripple height, $\eta_{e q}$ was the equilibrium height for the extant conditions (waves, currents, and sediment size), $\beta$ was a rate coefficient that depended on transport rate (wave mobility number or non-dimensionalized excess shear stress), and $T$ was a time scale (wave period or ratio of ripple mass/transport rate). When conditions were below threshold for mobilization, ripples were frozen in their pre-existing state. Otherwise, approximate solutions for Eq. (7) (and analogous formulae for ripple wavelength and orientation) were used to evolve ripple heights (wavelengths and orientations) toward equilibrium. The SW05 model was derived empirically from a large set of lab and field observations, and had the advantage of handling time-dependent evolution of ripple geometry for both waves and currents. The equilibrium values, rate coefficients, and time scales switched, depending on whether waves or currents generate the larger Shields parameters. In our ROMS implementation, bed stresses were calculated at each time step ( $\Delta t=4 \mathrm{~s}$ at finest grid resolution) using bed roughness calculated with Eq. (6) and ripple heights and wavelengths from the previous time step, and these bed stresses were used to update ripple geometry for model output and stress calculations in the next time step. 


\subsection{Model nesting and coupling methodology}

We used one-way grid nesting at four levels of resolution to provide boundary conditions for our numerical experiment. In one-way grid nesting applications, the coarser grid provides hydrodynamic information to the finer grid, but not vice versa. This can lead to discontinuities between computed solutions on the child grid and boundary conditions from the parent grid, but use of radiation conditions will allow the boundary condition to relax in consideration of the computed solution.

We ran the wave model SWAN on a coarse grid (grid 1;5-km resolution) for the entire US East Coast (R. He, North Carolina State University, pers. comm.), forcing with parametric time series of wave height, period, and direction from the Western North Atlantic model output of WAVEWATCH-III (Tolman, 1999), and wind components from the North American Mesoscale model (Rogers et al., 2005). At this grid level, a JONSWAP spectrum (Hasselmann et al., 1973) with 20-degree directional spreading was imposed. SWAN propagated the waves specified at the boundary, generated waves within the domain with the provided winds, and computed twodimensional wave spectra (frequency and direction) through time over the domain. We used the modification of Rogers et al. (2003), which moves wave energy from the high-frequency portion of the spectrum to the low-frequency portion. This counteracted the tendency of SWAN to overly dissipate low-frequency swell waves. Skill (Brier Skill Score, see below) for wave height exceeded 0.8 at nearby NDBC buoys (44004, 44008, 44018; on US East Coast grid). In all experiments, wave effects were restricted to bottomboundary layer calculations, and were not considered for computation of radiation stresses or mass transport. Pending implementation of additional methods such as the vortex-force formulation (Uchiyama et al., 2009) renders these effects beyond the scope of this paper.

We ran both ROMS and SWAN on an intermediate grid (grid 2) with a domain encompassing southern New England at 1000-m resolution (Fig. 3). Wave energy densities, as a function of frequency and direction through time, were extracted from the coarse grid and applied as boundary conditions at the edges of the intermediate grid 2 . Tidal forcing at the boundary was specified using tidal constituents (Wilkin, 2006), while subtidal forcing (for velocity, temperature, and salinity) was provided by the MABGOM model (He and Chen, in press). In two-way coupled applications, ROMS passes fields of water level and velocity to SWAN, while SWAN passes wave height, wave length, period, direction, and bottom orbital velocity. ROMS and SWAN were not coupled on grid 2, and test runs showed that two-way coupling generated only minor differences at significant computational expense.

ROMS and SWAN were run using two-way coupling on a finer intermediate grid (grid 3) which represented the region south of Martha's Vineyard at 200-m resolution (Fig. 3). Two-dimensional wave spectra from grid 2 were used for wave boundary conditions. Hydrodynamic boundary forcing was specified as time-series of water level, depth-averaged velocity, temperature, and salinity, all interpolated from the grid 2 model output. Radiation conditions were specified for depth-averaged velocity following Flather (1976) and for water level following Chapman (1985). These boundary conditions allowed the model to relax the imposed boundary values for outward-propagating volume transport and gravity waves (e.g., western boundary velocity during westward flow). Two-way coupling was performed by passing computed fields at 10 -min intervals.

The numerical experiments discussed in this paper were performed on the finest grid (grid 4), which represented the region surrounding MVCO with 40-m resolution (Fig. 3). Two-dimensional wave spectra from SWAN computations on grid 3 were used as wave boundary conditions for grid 4 , and water level, currents, temperature, and salinity from ROMS output on grid 3 were used to apply hydrodynamic forcing for grid 4 in the same fashion as described above. However, we adjusted the amplitude of current speeds to improve model agreement with acoustic Doppler current measurements at MVCO. In simulations made without this adjustment, depth-averaged velocity was overestimated while water level was well predicted (Fig. 4). We used T-TIDE (Pawlowicz et al., 2002) to identify the phase and amplitude of major tidal

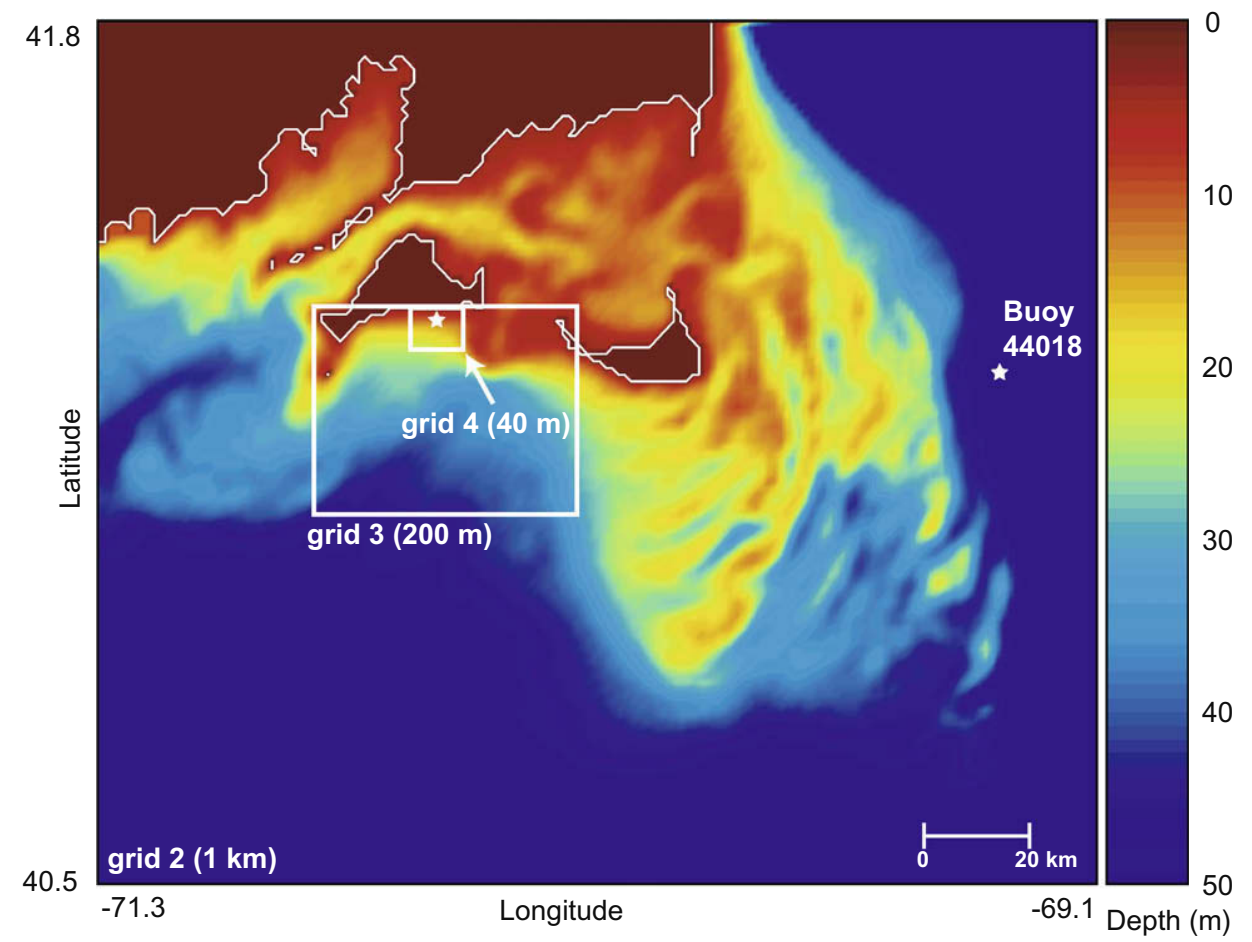

Fig. 3. ROMS and SWAN nested domains at $1 \mathrm{~km}$ (grid 2), $200 \mathrm{~m}$ (grid 3), and $40 \mathrm{~m}$ resolution (grid 4). 

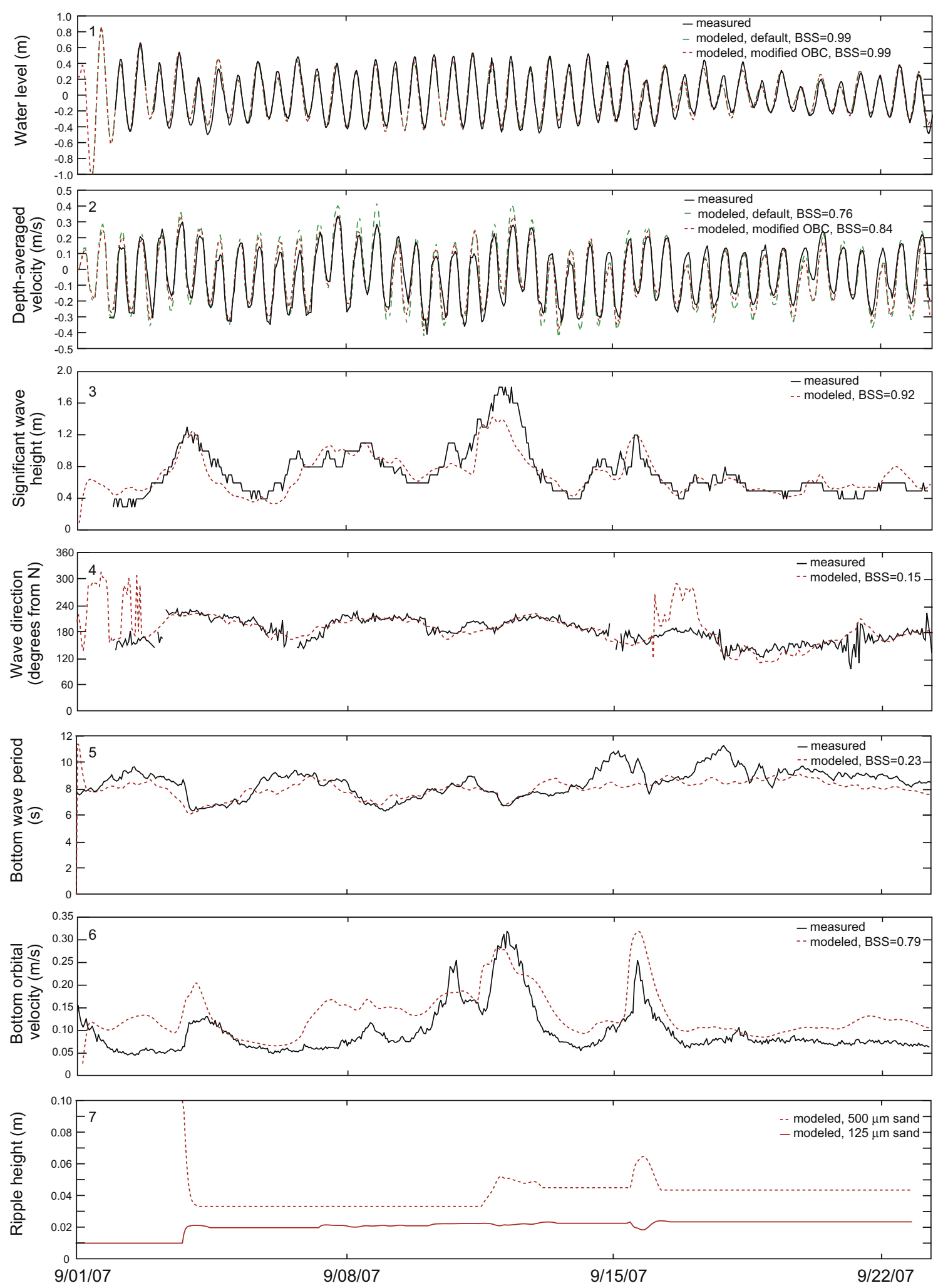

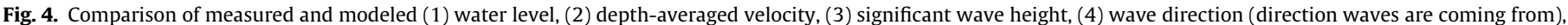

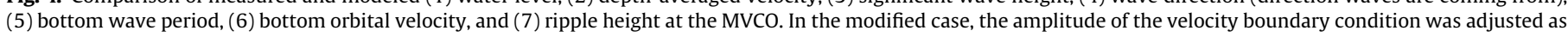
a sensitivity test. Water level was minimally affected by the modification. Ripple heights are from adjacent fine (125 $\mu \mathrm{m})$ and coarse ( $500 \mu \mathrm{m})$ sediment regions.

constituents in the MVCO data and model output, and multiplied the grid 3 output by a factor of 0.86 before using it as input to grid 4. This improved the Brier skill score (defined below) for modeled vs. measured depth-averaged current speed at MVCO from 0.76 to 0.84 (Fig. 4) and had little effect on the model skill for water level or current direction. Disagreement between the model and data on the subtidal timescale may be due to the neglect of wave effects or errors in the subtidal forcing at the $1 \mathrm{~km}$ grid level. Significant wave height, wave direction, bottom wave period, and orbital velocity at site MVCO were modeled with varying skill (Fig. 4). 
Orbital velocity, which exerts the most influence on ripple geometry, is overestimated by approximately $25 \%$ during the last wave event of the period; this would lead to a $25 \%$ increase in calculated equilibrium ripple height (Wiberg and Harris, 1994). Orbital velocity is also overestimated during low-energy periods, but ripples are not dynamic under these conditions. The orbital velocity skill score of 0.79 is towards the upper range of performance reported by Wiberg and Sherwood (2008), where orbital velocity was estimated using local surface wave measurements.

Sediment transport (suspended load and bedload) was activated for the grid 4 experiments. The model was initialized with a single bed layer and bimodal sediment distribution, with exclusively $0.5-\mathrm{mm}$ sand in the coarse regions and exclusively 0.125 $\mathrm{mm}$ sand in the fine regions, as delineated by the regions of low (dark) and high (bright) acoustic backscatter amplitude, respectively (Fig. 2). Ripple dimensions were initialized with height $\eta_{r}=0.1 \mathrm{~m}$ and wavelength $\lambda_{r}=0.6 \mathrm{~m}$ on the coarse patches, and $\eta_{r}=0.01 \mathrm{~m}$ and $\lambda_{r}=0.1 \mathrm{~m}$ over the fine patches, based on diver observations and previous studies (Goff et al., 2005; Traykovski, 2007). Transport during our three-week model simulations produced mixed sediment in computational cells at the coarse-fine boundaries, but did not alter the boundaries. The computed ripple height over fine and coarse domains, along the $12 \mathrm{~m}$ isobath, demonstrates the response of the sediment bed to wave forcing (Fig. 4). As wave orbital velocity increased during the event of 9/03/2007, coarse sand ripple heights decreased from the initial value to an equilibrium value of $0.03 \mathrm{~m}$, while fine sand ripple heights increased to $0.02 \mathrm{~m}$. The two subsequent large wave events increased coarse sand ripple heights to a maximum of $0.06 \mathrm{~m}$, and slightly decreased fine sand ripple heights. Modeled ripple geometries are well constrained with $\eta_{r}$ ranging between 0.02 and $0.06 \mathrm{~m}$ and $\lambda_{r}$ ranging between 0.16 and $0.45 \mathrm{~m}$ near the MVCO location. These geometries are consistent with diver observations and Traykovski's (2007) observations for lower-energy periods during the 2005 field campaign at MVCO.

\subsection{Model simulations and skill assessment}

Three numerical experiments were conducted on the finest grid (grid 4) to evaluate different implementations of roughness: (1) uniform roughness with $z_{0}=0.0001 \mathrm{~m}$ (case UR); (2) variable apparent roughness $z_{0 a}$ computed from the wave-current interaction bottom-boundary layer model with inner roughness based on the sum of simulated sediment transport $z_{0 S T}$ and grain roughness $z_{0 N}$ (case WC); and (3) same as case WC with the addition of rippleroughness contribution $z_{0 B F}$ as input to the wave-current bbl model (case RR). The effective roughness of the wave-current apparent roughness and the ripple-induced roughness is expected to be an order of magnitude greater than that of grains or saltation. Therefore case WC mainly represents the effect of wave-current interaction and the calculated apparent roughness, using a uniform inner roughness. The simulation spanned 9/1/2007-9/23/2007, a period which covered a full spring-neap cycle, and three wave events exceeding $1 \mathrm{~m}$ at site MVCO.

We used the Brier skill score and the graphic method of Taylor (2001) to assess changes in model performance. The Brier skill score (Murphy and Epstein, 1989) varies between 1 for perfect skill and negative infinity for poor skill, and is defined as

$B S S=1-\frac{\sum_{i=1}^{n}\left(x_{i}-y_{i}\right)^{2}}{\sum_{i=1}^{n}\left(x_{i}-c_{i}\right)^{2}}$

where $n$ is the number of points in a time series for model-data comparison, $x_{i}$ is $i$ th observation in the measurements, $y_{i}$ is the corresponding modeled value, and $c_{i}$ is a point in a null-model timeseries. The null-model used here is the mean of the time-series.
The BSS, used with hourly data $(n=540)$, evaluated relative errors in model results at the tidal timescale; model performance in a residual sense can be evaluated by inspecting means over the simulation period. The Taylor diagram allowed us to compare model results with data in terms of correlation, standard deviation, and RMS difference, on a single plot. Values were normalized by the standard deviation of the data to allow data of differing types to be presented on the same scale.

\section{Results}

\subsection{Model skill: current magnitude and direction in the water column}

Skill for current speed in the upper water column (9.2$12.7 \mathrm{mab}$ ) at the MVCO ADCP was highest for case UR and lowest for case RR; the converse was true in the lower part of the measured water column (Table 2). Depth-averaged velocity skill was minimally affected by roughness changes, and depth-averaged directional skill was maximized under case RR. At site USGS, current magnitude skill peaked under case UR at all depths, though direction was simulated best with case WC.

The general near-surface westward flow was retarded under case RR, with the influence maximized between the 10 and $14-\mathrm{m}$ isobath (Fig. 5). The increase in drag due to the ripple-roughness contribution was responsible for the reduction in flow velocity. Reduced near-surface skill at both ADCP sites for case RR indicated that this reduction in westward flow was inconsistent with observations. Conversely, under case UR residual westward velocities at the deepest ADCP bins (3.22 mab) were overestimated; increasing roughness reduced these velocities in line with observations.

\subsection{Model skill: near-bed current magnitude and direction}

Near-bed current magnitudes were modeled with similar skill as currents higher in the water column, though the effect of roughness was varied between measurement locations (Fig. 6). At most sites, case UR produced the highest skill, though performance for case WC declined only slightly overall, and showed skill increases at 4 of 10 sites. Case RR showed a minimal increase in skill from case UR at two sites; both are located near the MVCO location. There was a pattern to the changes in skill; increasing roughness corresponded to increased skill at southeastern sites, and decreased skill at western sites. The same trend was observed for current direction.

Decreased skill at the western sites was largely due to changes in the timing of velocity, due to increased drag for case RR. Though flood and ebb magnitudes appeared to be congruent with observa-

Table 2

Brier skill scores for current magnitude and direction from ADCP sites. Skill values were computed from averaged velocities over indicated depth bins. Bold values indicate peak skill for each variable. All cases used the improved open boundary condition (OBC).

\begin{tabular}{|c|c|c|c|c|c|c|}
\hline & \multicolumn{2}{|c|}{ Case UR } & \multicolumn{2}{|c|}{ Case WC } & \multicolumn{2}{|c|}{ Case RR } \\
\hline & Mag & Dir & Mag & Dir & Mag & Dir \\
\hline \multicolumn{7}{|l|}{ MVCO } \\
\hline $3.2-6.2 \mathrm{mab}$ & 0.73 & 0.45 & 0.75 & 0.53 & 0.79 & 0.62 \\
\hline $6.2-9.2 \mathrm{mab}$ & 0.74 & 0.53 & 0.72 & 0.47 & 0.73 & 0.60 \\
\hline $9.2-12.7 \mathrm{mab}$ & 0.68 & 0.45 & 0.63 & 0.47 & 0.60 & 0.45 \\
\hline Depth-averaged & 0.74 & 0.54 & 0.72 & 0.55 & 0.72 & 0.63 \\
\hline \multicolumn{7}{|l|}{ USGS } \\
\hline $3.2-6.2 \mathrm{mab}$ & 0.85 & 0.64 & 0.85 & 0.69 & 0.84 & 0.65 \\
\hline $6.2-9.2 \mathrm{mab}$ & 0.85 & 0.60 & 0.84 & 0.66 & 0.81 & 0.60 \\
\hline $9.2-12.7 \mathrm{mab}$ & 0.80 & 0.50 & 0.74 & 0.51 & 0.67 & 0.40 \\
\hline Depth-averaged & 0.85 & 0.67 & 0.83 & 0.70 & 0.79 & 0.62 \\
\hline
\end{tabular}



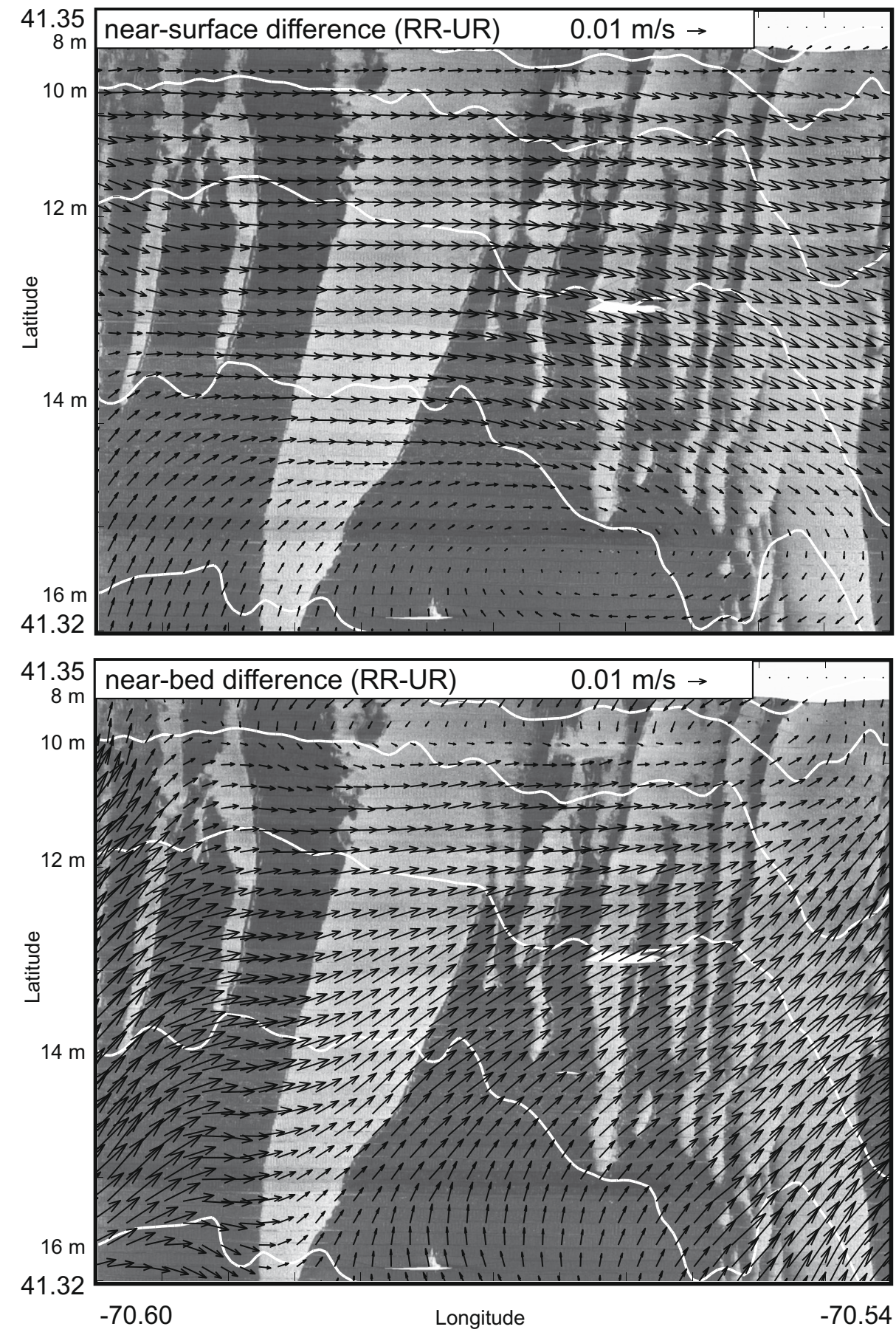

Fig. 5. Vector differences (cases UR-case RR) for time-mean near-surface and near-bed current velocities.

tions for case RR (Fig. 7), increased drag altered the phasing of flood and ebb tides, thereby reducing skill on the tidal timescale. Demeaned flood and ebb directions were largely unchanged between cases. Mean velocity directions were shifted clockwise with increased roughness (Figs. 5 and 7), consistent with observations at five of the near-bed sites. Both the data and model showed a general mean near-bed circulation to the west; the modeled westward flow diverged near the $12-\mathrm{m}$ isobath, though the data did not display that divergence. Poorer agreement at the shallowest sites may be due to the neglect of wave radiation stresses in the model or instrument compass problems.

Cases UR and WC appeared largely indistinguishable with regard to current magnitude and direction on the Taylor diagram, while case RR appeared to increase error at most sites (Fig. 8). Standard deviations for velocity magnitude were closer to the data in case RR, as the tidal timescale velocity magnitudes were lowered by increased roughness. The velocity phasing errors for case RR were not represented in the standard deviation values, but were evident in the lowered correlation values. Typical error metrics such as bias, RMSE, and normalized RMSE suggest lower error for case RR, but do not account for the reduced temporal correlation due to excessive drag (Table 3).

In the frequency domain, modeled near-bed currents at site USGS for case UR matched the phase of the dominant $\mathrm{M}_{2}$ constituent, though the amplitude was modeled best under case RR (Table 4). Case RR gave rise to larger errors for $\mathrm{M}_{2}$ phasing, which 


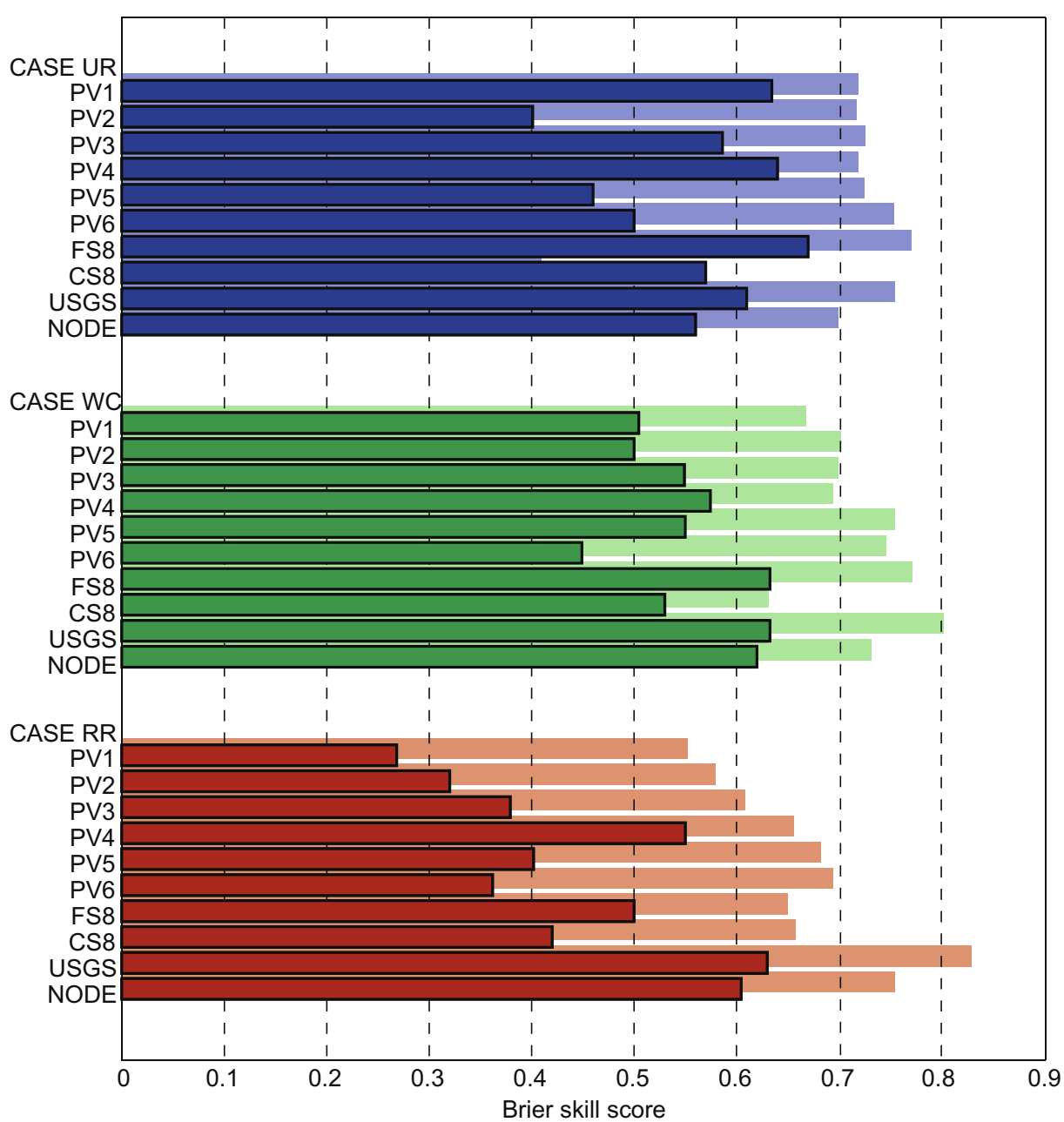

Fig. 6. Brier skill score at all near-bed sites for current direction (foreground, bold) and magnitude (background, shaded).

is evident in the Brier Skill Score, but not RMSE values. For total amplitude, case WC generated the least error. The frequency domain analysis demonstrates the difficulty of simulating magnitudes and phasing while simultaneously testing bottom roughness parameterizations and boundary conditions.

\subsection{Model skill: bottom shear stress and turbulence dissipation}

Skill for current-induced shear stresses was maximized using an inner roughness that was substantially smaller than typical parameterizations (Table 5). The addition of wave-current interaction (and the increased apparent roughness) yielded larger stresses (Figs. 8 and 9); skill was still reasonable though decreased relative to case UR. Case RR, with the addition of ripple roughness, significantly overestimated stresses. In terms of turbulence dissipation, case WC performed with the highest skill, while case UR and case RR underestimated and overestimated dissipation, respectively. Error for case RR was increased during wave-affected periods, when modeled ripples were larger (09/01/07-09/04/07; 09/10/07-09/ $14 / 07)$, and production of turbulence was greater. Sediment-induced stratification may have also been present during these periods, which would dampen turbulence and reduce shear stress. The higher skill for case UR with respect to stresses, and case WC with respect to dissipation, suggests that performance of wave-current interaction and turbulence closure routines were maximized with different values of roughness. We also tested the effect of vertical resolution by varying the vertical stretching parameter to increase near-bed vertical resolution. Under case WC, increased near-bed resolution did not increase skill for stresses (or near-bed currents); this suggests that the original vertical resolution was sufficient to describe the velocity profile and for computations of turbulence and shear stress.

\section{Discussion}

\subsection{Effect of roughness on model skill}

The response of modeled current magnitudes and directions to roughness formulation suggests that near-bed circulation is not better-predicted by including spatial and temporal variation in hydrodynamic bottom roughness. Skill was improved higher in the water column at two of the ten sites (MVCO and USGS); this is consistent with increases in near-bed skill at those same sites. However all other near-bed sites showed a decrease in skill when ripple roughness was activated, due to a substantial increase in drag over the coarse sand patches. The hypothesis that inclusion of ripple-induced roughness (with the present parameterization) increases model performance is therefore not supported; use of uniform bed roughness (which may be tuned to maximize skill) along with a wave-current interaction routine performs with the best overall skill with respect to current magnitude, direction, and stresses. Comparison of the individual contribution of roughness components (Table 6 ) indicates that ripple-induced roughness is the dominant term in the increased apparent roughness. 

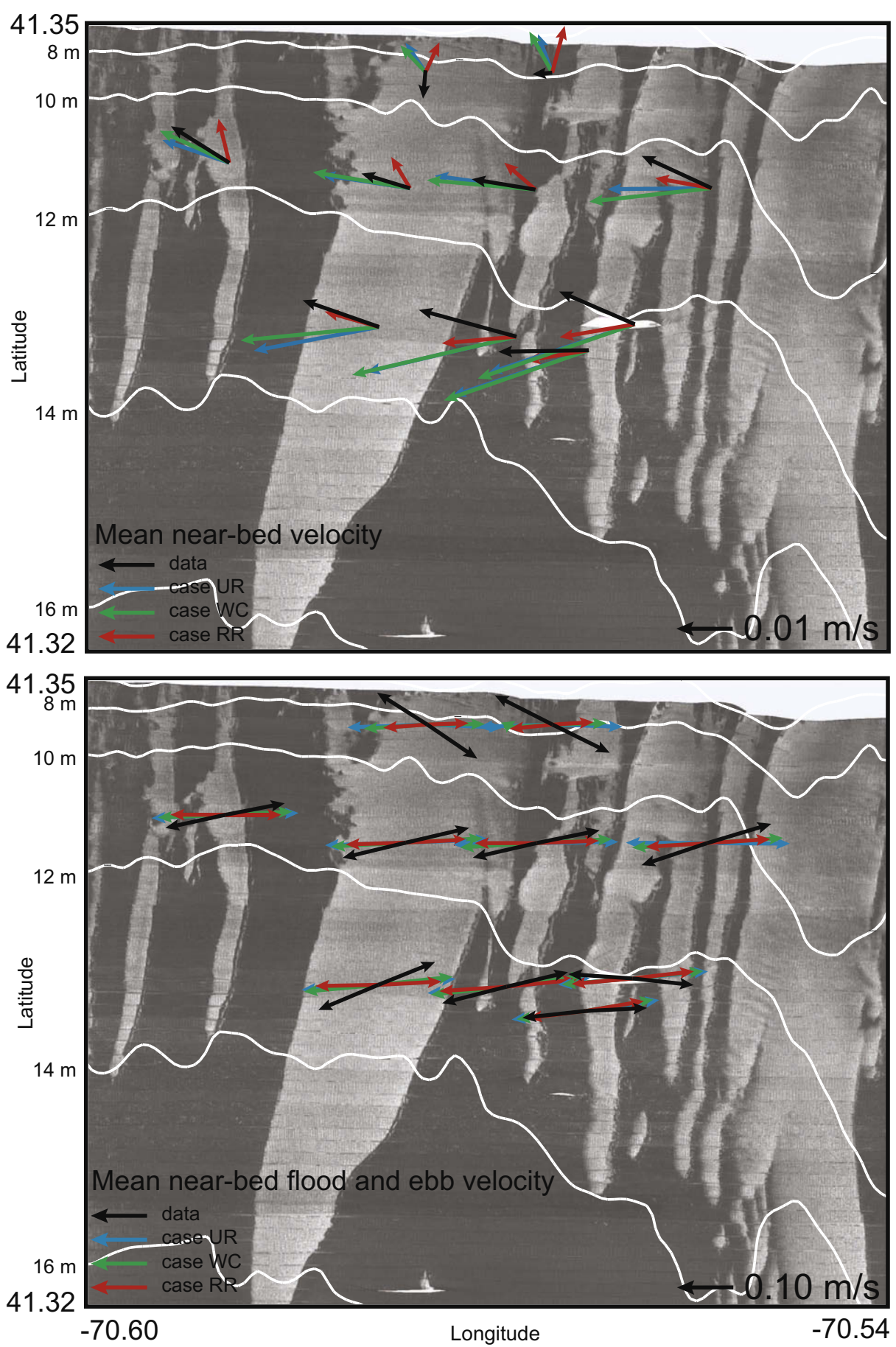

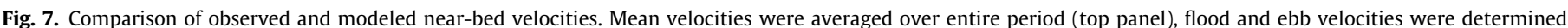


Note change in arrow scale between two panels.

Overestimation of orbital velocity by the wave model (Fig. 4) may lead to an overestimate of ripple height (and inner roughness), but this study shows that with the lowest published values of $a_{r}$ (and therefore ripple-induced roughness) the skill of the hydrodynamic model is reduced. There is more uncertainty in the parameterization of ripple-induced roughness than uncertainty in the wave and ripple models. Further work will test the skill of time-dependent ripple models in the nearshore environment.

Our approach involved first maximizing skill using a uniform roughness at all grid levels, with a given set of boundary conditions, and then varying roughness parameterization at the finest grid level. Alternatively, a spatially variable roughness could have been implemented at all scales (e.g. using depth as a surrogate for roughness where bedform data were not available), and boundary conditions could be altered for agreement. That exercise, however, does not produce insight towards the effect of bottom roughness parameterization on regional applications where bottom roughness length is unknown, but thought to be highly variable (i.e. over sorted bedforms). Tuning roughness length at the multiple near-bed sites, using data assimilation, does not provide guidance for regional applications or model development either. The implementation of boundary conditions and bottom roughness 


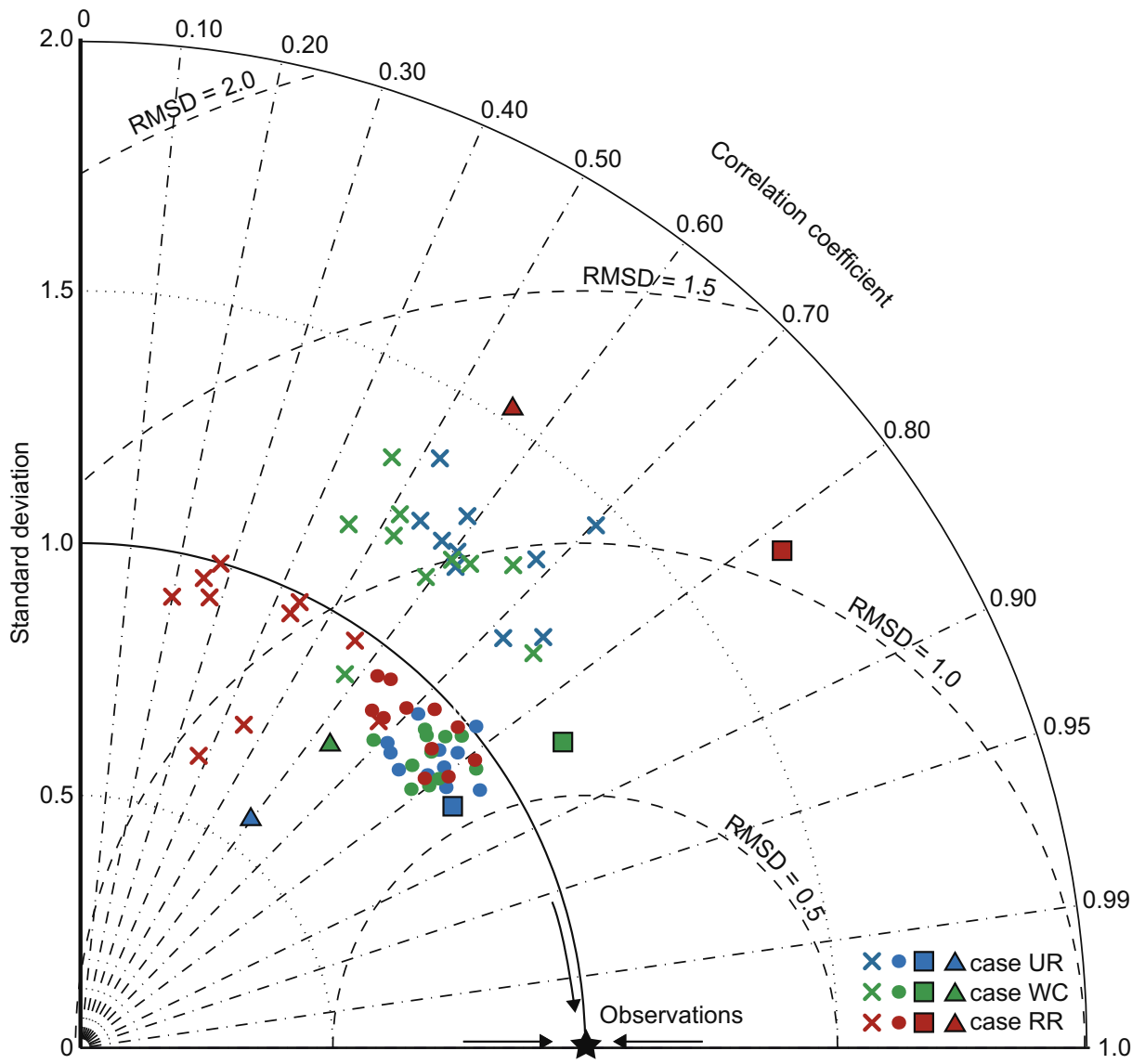

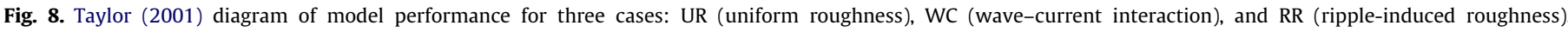



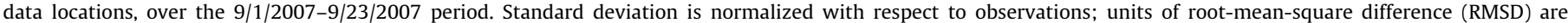
standard deviations of the data. Improved agreement moves points toward observations along indicated trajectory toward the star.

Table 3

Bias, root-mean-square error (RMSE), and normalized root-mean-square error (NRMSE) for modeled near-bed current magnitudes at all sites, for three cases.

\begin{tabular}{|c|c|c|c|c|c|c|c|c|c|}
\hline \multirow[t]{2}{*}{ Site ID } & \multicolumn{3}{|c|}{$\operatorname{Bias}(\mathrm{m} / \mathrm{s})$} & \multicolumn{3}{|c|}{ RMSE (m/s) } & \multicolumn{3}{|c|}{ NRMSE } \\
\hline & UR & WC & $\mathrm{RR}$ & UR & WC & $\mathrm{RR}$ & UR & WC & $\mathrm{RR}$ \\
\hline PV1 & -0.03 & -0.02 & -0.01 & 0.06 & 0.05 & 0.05 & 0.27 & 0.25 & 0.23 \\
\hline PV2 & -0.04 & -0.03 & -0.01 & 0.07 & 0.06 & 0.05 & 0.28 & 0.26 & 0.23 \\
\hline PV3 & -0.04 & -0.03 & -0.01 & 0.07 & 0.06 & 0.05 & 0.30 & 0.28 & 0.25 \\
\hline PV4 & -0.04 & -0.03 & -0.01 & 0.07 & 0.06 & 0.05 & 0.26 & 0.25 & 0.21 \\
\hline PV5 & -0.03 & -0.03 & -0.01 & 0.06 & 0.06 & 0.05 & 0.24 & 0.22 & 0.19 \\
\hline PV6 & -0.04 & -0.03 & -0.02 & 0.06 & 0.06 & 0.05 & 0.25 & 0.24 & 0.21 \\
\hline FS8 & -0.02 & 0.00 & 0.02 & 0.04 & 0.04 & 0.04 & 0.16 & 0.15 & 0.19 \\
\hline CS8 & -0.04 & -0.02 & 0.01 & 0.05 & 0.04 & 0.03 & 0.25 & 0.19 & 0.16 \\
\hline USGS & -0.02 & -0.02 & 0.00 & 0.04 & 0.04 & 0.03 & 0.19 & 0.16 & 0.14 \\
\hline NODE & -0.02 & -0.02 & 0.00 & 0.05 & 0.04 & 0.04 & 0.21 & 0.20 & 0.18 \\
\hline
\end{tabular}

parameterization must depend on the goals of the modeling study and the availability of field data. If boundary conditions are known with high accuracy, then data assimilation of near-bed currents may help describe variability in bed friction. In the case presented here, the actual nature of the bed is well known, but the implementation of the bed in ocean models must still be tested rigorously. Our results suggest that the parameterization of roughness due to ripples is more complicated than Eq. (6), and requires further investigation with regards to ripple shape and orientation. Ideally, the influence of ripples should be a function of orientation, where drag is minimized in situations of bedform-parallel tidal currents and maximized for bedform-normal tidal currents. Testing such an algorithm would require a field setting where wave direction is not consistently normal to the tidal currents (unlike the setting described here).

There are two general approaches to model tuning: a top-down and a bottom-up approach. With the former, if modeled water levels and currents over the domain are accurate, then the bottomboundary layer formulation is considered adequate. With the latter

Table 4

Observed and modeled tidal constituents for five largest observed constituents, at site USGS. Sum of all constituents includes constituents not shown in table.

\begin{tabular}{|c|c|c|c|c|c|c|c|c|}
\hline \multirow[t]{2}{*}{ Constituent } & \multicolumn{2}{|l|}{ Observed } & \multicolumn{2}{|l|}{ Case UR } & \multicolumn{2}{|l|}{ Case WC } & \multicolumn{2}{|l|}{ Case RR } \\
\hline & Amplitude (m/s) & Phase (deg) & Amplitude (m/s) & Phase (deg) & Amplitude (m/s) & Phase (deg) & Amplitude (m/s) & Phase (deg) \\
\hline $\mathrm{M}_{2}$ & 0.116 & 210 & 0.149 & 210 & 0.138 & 207 & 0.114 & 202 \\
\hline $\mathrm{S}_{2}$ & 0.025 & 239 & 0.033 & 242 & 0.028 & 243 & 0.023 & 240 \\
\hline $\mathrm{K}_{1}$ & 0.017 & 147 & 0.017 & 147 & 0.014 & 145 & 0.009 & 140 \\
\hline $\mathrm{O}_{1}$ & 0.014 & 266 & 0.011 & 297 & 0.010 & 284 & 0.005 & 262 \\
\hline $\mathrm{M}_{6}$ & 0.011 & 40 & 0.011 & 31 & 0.009 & 29 & 0.008 & 44 \\
\hline Sum of all constituents & 0.218 & & 0.256 & & 0.237 & & 0.187 & \\
\hline
\end{tabular}


Table 5

Brier skill scores and mean values for current-induced bottom shear stress and turbulence dissipation from site NODE. Bold values indicate peak skill for each variable.

\begin{tabular}{|c|c|c|c|c|}
\hline & Data & Case UR & Case WC & Case RR \\
\hline Stress skill & - & 0.61 & 0.51 & 0.29 \\
\hline Mean stress value (Pa) & 0.041 & 0.036 & 0.048 & 0.072 \\
\hline Dissipation skill & - & 0.45 & 0.50 & 0.32 \\
\hline Mean dissipation value $(\mathrm{W} / \mathrm{kg})$ & $1.53 \times 10^{-6}$ & $0.65 \times 10^{-6}$ & $0.94 \times 10^{-6}$ & $2.20 \times 10^{-6}$ \\
\hline
\end{tabular}

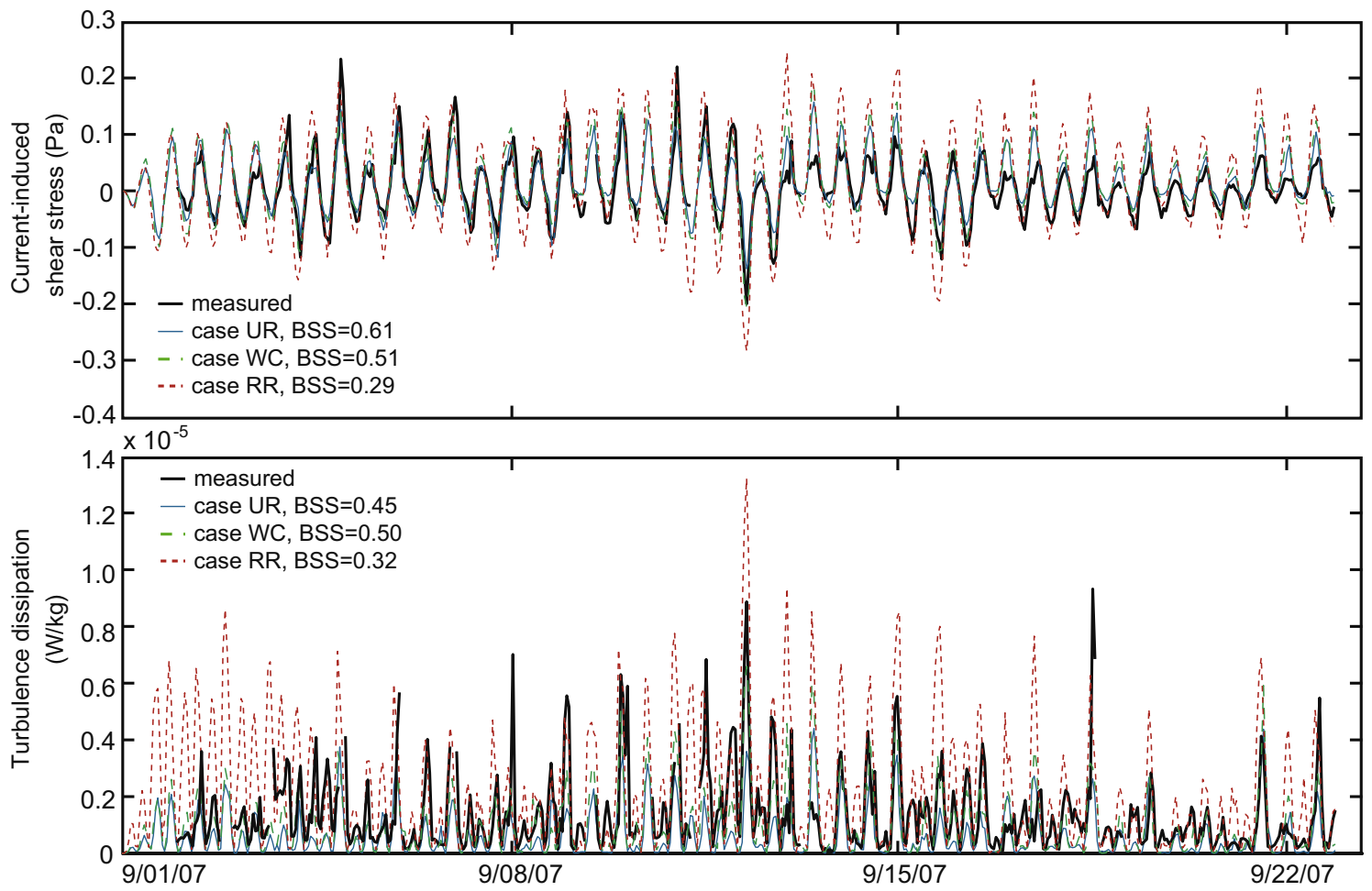

Fig. 9. Comparison of measured and modeled current-induced stresses and turbulence dissipation from three roughness cases.

Table 6

Example of mean and maximum modeled apparent outer roughness $\left(z_{0 a p p}\right)$ in the presence of waves, and inner roughness $\left(z_{0}\right)$ contributions from ripples $\left(z_{O B F}\right)$, sediment grains $\left(z_{0 N}\right)$, and saltation $\left(z_{0 S T}\right)$. All values are from fine and coarse sand model locations, at $12 \mathrm{~m}$ depths, nearest the MVCO. All values in meters.

\begin{tabular}{llllll}
\hline \multirow{2}{*}{ Roughness } & \multicolumn{2}{c}{$125 \mu \mathrm{m}$ sand } & & \multicolumn{2}{c}{$500 \mu \mathrm{m}$ sand } \\
\cline { 2 - 3 } \cline { 5 - 6 } \cline { 5 - 6 } & Mean $(\mathrm{m})$ & Max $(\mathrm{m})$ & & Mean $(\mathrm{m})$ & Max $(\mathrm{m})$ \\
\hline$z_{\text {Oapp }}$ (with uniform $z_{0}$ ) & $2.0 \times 10^{-3}$ & $2.0 \times 10^{-2}$ & & $2.0 \times 10^{-3}$ & $2.0 \times 10^{-2}$ \\
$z_{\text {Oapp }}$ (with calculated $\left.z_{0}\right)$ & $9.0 \times 10^{-3}$ & $3.5 \times 10^{-2}$ & & $1.9 \times 10^{-2}$ & $9.1 \times 10^{-2}$ \\
$-z_{\text {OBF }}$ & $8.0 \times 10^{-4}$ & $1.0 \times 10^{-3}$ & & $2.0 \times 10^{-3}$ & $4.0 \times 10^{-3}$ \\
$-z_{\text {ON }}$ & $5.0 \times 10^{-5}$ & $5.0 \times 10^{-5}$ & & $5.0 \times 10^{-5}$ & $5.0 \times 10^{-5}$ \\
$-z_{\text {OST }}$ & $2.0 \times 10^{-6}$ & $8.9 \times 10^{-6}$ & & $2.9 \times 10^{-6}$ & $3.0 \times 10^{-5}$ \\
\hline
\end{tabular}

approach, the bottom-boundary layer formulation must reproduce measured near-bed currents and/or stresses before a determination can be made for the water column. Here we have attempted a hybrid of the two by considering depth-averaged currents, near-bed currents, and bed stresses. This study shows that adequate skill can be achieved for currents while bed stresses are poorly modeled; skill can be increased for bed stresses by incorporating a wave-current interaction routine, without sacrificing skill for currents.

\subsection{Wave-current interaction and ripple roughness parameterization}

Model skill in terms of circulation was affected minimally by parameterization of roughness (Fig. 8), but bottom stresses were significantly overestimated using standard values of parameter $a_{r}$. Using measured near-bed and wave orbital velocities, Madsen's (1994) wave-current model was used to estimate current stresses. The derived estimates agreed with the covariance stress estimates when an average $z_{0}=1 \times 10^{-4} \mathrm{~m}$ was used (the uniform value used above). This is significantly less than the roughness associated with $0.01 \mathrm{~m}$ high and $0.1 \mathrm{~m}$ long ripples $\left(a_{r}=0.267\right.$, $z_{0} \sim 2.7 \times 10^{-4} \mathrm{~m}$ ), but larger than the roughness associated with the sand grains themselves $\left(z_{0}=k_{s} / 30=2.5 D_{50} / 30=1 \times 10^{-5} \mathrm{~m}\right.$ for $125 \mu \mathrm{m}$ sand). At each measurement time, a $z_{0}$ was found that maximizes agreement between the derived stresses and covariance stress estimates. This time series of $z_{0}$ (not shown) demonstrated large fluctuations that may be due to physical changes in roughness, or inherent noise in the measurement process (Gross et al., 1993). There was little coherence between calculated $z_{0}$ and physical measurements such as wave height or wave orbital velocity (a surrogate for ripple formation). This suggests that use of an intermediate $z_{0}$ (more than the grain contribution, but less than ripple contribution using typical values of $a_{r}$ ) can be used to adequately model current-induced stresses, though this may be due to the relative alignment of the dominant currents and ripple crests, the shape of the ripples, or sediment-induced stratification. There is a directional trend to the model-data mismatch: stresses generated by westward flows are consistently overestimated by the model (in comparison to eastward flows). This may indicate the presence of sediment stratification during westward (ebb) flows. 
Although inclusion of ripple-induced roughness produces minor changes in model skill, the physical presence of ripples on the seabed generates increased turbulence, thereby retaining coarser fractions, winnowing finer fractions, and preserving grain-size distributions. The stress measurements (via the covariance technique) may have been affected by sediment-induced stratification; this may account for traditional values of $a_{r}$ producing modeled bottom stresses in excess of measurements. This would tend to dampen turbulence and reduce bottom shear stress, while model estimates (unstratified conditions) would overestimate stresses under the same flow, wave, and bedform conditions. It should also be noted that the turbulence model used here (in combination with the wave-current interaction routine) may not be optimal for simulating stresses and turbulence under a wave field; other methods such as Mellor's (2002) method should be tested in a similar context. These limitations of the model preclude a definitive determination of the correct parameterization of roughness with regards to bottom shear stress, but the findings regarding circulation are unaffected.

\section{Conclusion}

We developed a regional model for hydrodynamics, waves, and sediment transport on the southern New England inner shelf, where dynamic bedforms alter the physical roughness and presumably, the hydrodynamic roughness. We found that use of variable roughness in this coastal ocean model does not significantly improve skill for circulation, stresses, or turbulence dissipation, despite a large contrast in physical roughness. The widely used method of varying a uniform roughness to maximize agreement with data appears to generate the same level of skill with respect to circulation; patterns of sediment transport, however, will be dependent on local gradients in roughness and bottom shear stress. Performance with respect to stresses may have been complicated by the effect of sediment-induced stratification; unrepresented stratification within the model may account for overestimation of stresses. The relationship between ripple geometry and roughness is modulated by a coefficient $\left(a_{r}\right)$ which has a wide range in the literature; this range probably reflects missing information related to ripple geometry (e.g. shape, skewness). The value of $a_{r}$ may also be dependent on the orientation of the ripples with respect to the dominant flow direction. In our study area, wave crests are oriented roughly parallel to shore, and dominant currents are in the alongshore direction. Therefore it is possible that the flow field does not perceive the aligned ripples as additive drag elements.

This study did not investigate the importance of hydrodynamic roughness on spatial patterns of sediment transport (due to data limitations), but it is assumed that large contrast in ripple heights maintains turbulence over coarse deposits and prevents deposition of finer sand fractions. Further work is needed to address the partitioning of form drag and skin friction within the model: sediment transport is initiated by the skin friction component, but turbulence is affected by the combined contribution with spatial variations over the ripple field, which highlights the need for consistent modeling of each component. Maintenance of the sorted grain-size features at the study location (and for sediment transport in general) depends on a feedback between roughness, turbulence, and advection of finer fractions away from regions of larger ripples (Murray and Thieler, 2004). The features here have maintained position over yearly timescales, and this mechanism must be partially responsible. Further study, using the time-dependent ripple model, will eludicate the event-scale formation of ripple fields, the associated turbulence, and advection of sediment on the inner shelf.

\section{Acknowledgements}

Funding was provided through the Office of Naval Research Ripples DRI and U.S. Geological Survey Coastal and Marine Geology Program. We thank T. Herbers, J. Trowbridge, P. Traykovski, S. Lentz, J. Warner, J. Wilkin, R. He, R. Signell, B. Armstrong and M. Arsenault for assistance with data and modeling. We also thank N. Plant, X. Bertin and the anonymous reviewers for their constructive comments. Guillaume Maze provided the Taylor diagram plotting code. Use of firm names is for descriptive purposes only, and does not imply endorsement by the US Government. This paper is dedicated to Bela Marie and Rohan Kamal Ganju.

\section{References}

Booij, N., Ris, R.C., Holthuijsen, L.H., 1999. A third-generation wave model for coastal regions 1 . Model description and validation. Journal of Geophysical Research 104 (C4), 7667-7681.

Butman, B., Sherwood, C.R., Dalyander, P.S., 2008. Northeast storms ranked by wind stress and wave-generated bottom stress observed in Massachusetts Bay, 19902006. Continental Shelf Research 28 (10-11), 1231-1245.

Cacchione, D.A., Drake, D.E., Grant, W.D., Tate, G.B., 1984. Rippled scour depressions on the inner continental shelf off central California. Journal of Sedimentary Petrology 54 (4), 1280-1291.

Chapman, D.C., 1985. Numerical treatment of cross-shelf open boundaries in a barotropic coastal ocean model. Journal of Physical Oceanography 15, 10601075.

Chassignet, E.P., Arango, H., Dietrich, D., Ezer, T., Ghil, M., Haidvogel, D.B., Ma, C.C. Mehra, A., Paiva, A.M., Sirkes, Z., 2000. DAMÉE-NAB: the base experiments. Dynamics of Atmospheres and Oceans 32 (3-4), 155-183.

Davies, A.M., Lawrence, J., 1995. Modeling the effect of wave-current interaction on the three-dimensional wind-driven circulation of the Eastern Irish Sea. Journal of Physical Oceanography 25, 29-45.

Denny, J.F., Danforth, W.W., Foster, D.S., Sherwood, C.R., 2009. Geophysical data collected off the south shore of Martha's Vineyard, Massachusetts, U.S. Geological Survey Open-File Report 2008-1288.

Flather, R.A., 1976. A tidal model of the northwest European continental shelf. Memoires de la Societe Royale des Sciences de Liege 6, 141-164.

Goff, J.A., Jenkins, C.J., Williams, S.J., 2008. Seabed mapping and characterization of sediment variability using the usSEABED data base. Continental Shelf Research 28 (4-5), 614-633.

Goff, J.A., Mayer, L.A., Traykovski, P., Buynevich, I., Wilkens, R., Raymond, R., Glang, G., Evans, R.L., Olson, H., Jenkins, C., 2005. Detailed investigation of sorted bedforms, or "rippled scour depressions", within the Martha's Vineyard Coastal Observatory, Massachusetts.. Continental Shelf Research 25 (4), 461-484.

Grant, W.D., Madsen, O.S., 1979. Combined wave and current interaction with a rough bottom. Journal of Geophysical Research 84 (C4), 1797-1808.

Grant, W.D., Madsen, O.S., 1982. Moveable bed roughness in unsteady oscillatory flow. Journal of Geophysical Research 87 (C1), 469-481.

Gross, T.F., Isley, A.E., Sherwood, C.R., 1993. Estimation of stress and bed roughness during storms on the Northern California Shelf. Continental Shelf Research 12, 389-413.

Haidvogel, D.B., Arango, H., Budgell, W.P., Cornuelle, B.D., Curchitser, E., Di Lorenzo, E., Fennel, K., Geyer, W.R., Hermann, A.J., Lanerolle, L., Levin, J., McWilliams, J.C. Miller, A.J., Moore, A.M., Powell, T.M., Shchepetkin, A.F., Sherwood, C.R., Signell, R.P., Warner, J.C., Wilkin, J., 2008. Ocean forecasting in terrain-following coordinates: formulation and skill assessment of the regional ocean modeling system. Journal of Computational Physics 227 (7), 3595-3624.

Haidvogel, D.B., Arango, H.G., Hedstrom, K., Beckmann, A., Malanotte-Rizzoli, P., Shchepetkin, A.F., 2000. Model evaluation experiments in the North Atlantic Basin: simulations in nonlinear terrain-following coordinates. Dynamics of Atmospheres and Oceans 32 (3-4), 239-281.

Hasselmann, K. et al., 1973. Measurements of wind-wave growth and swell decay during the Joint North Sea Wave Project (JONSWAP). Ergänzungshelf zur Deutschen Hydrographischen Zeitschrift, Reihe A 8 (12), 95.

He, R., Chen, K., in press. Investigation of the northeastern North America coastal circulation using a regional-scale ocean model. Journal of Geophysical Research.

He, R., Wilkin, J.L., 2006. Barotropic tides on the southeast New England shelf: a view from a hybrid data assimilative modeling approach. Journal of Geophysical Research 111, C08002, doi: 10.1029/2005JC003254.

Huntley, D.A., 1988. A modified inertial dissipation method for estimating seabed stresses at low Reynolds numbers, with application to wave/current boundary layer measurements. Journal of Physical Oceanography 18, 339-346.

Jones, J.E., Davies, A.M., 1998. Storm surge computations for the Irish Sea using a three-dimensional numerical model including wave-current interaction. Continental Shelf Research 18, 201-251.

Lopes, J.F., Dias, J.M., 2007. Residual circulation and sediment distribution in the Ria de Aveiro lagoon, Portugal. Journal of Marine Systems 68, 507-528.

Lu, X., Zhang, J., 2006. Numerical study on spatially varying bottom friction coefficient of a 2D tidal model with adjoint method. Continental Shelf Research 26, 1905-1923. 
Madsen, O.S., 1994. Spectral wave-current bottom boundary layer flows. In: Proc. of the 24th International Conference Coastal Engineering Research Council, Kobe, Japan, p. 15.

Mellor, G., 2002. Oscillatory bottom boundary layers. Journal of Physical Oceanography 32, 3075-3088.

Murphy, A.H., Epstein, E.S., 1989. Skill scores and correlation coefficients in model verification. Monthly Weather Review 117, 572-582.

Murray, A.B., Thieler, E.R., 2004. A new hypothesis and exploratory model for the formation of large-scale inner-shelf sediment sorting and "rippled scour depressions". Continental Shelf Research 24 (3), 295-315.

Nicolle, A., Karpytchev, M., 2007. Evidence for spatially variable friction from tidal amplification and asymmetry in the Pertuis Breton (France). Continental Shelf Research 27, 2346-2356.

Nielsen, P., 1992. Coastal bottom boundary layers and sediment transport. World Scientific, Singapore. 324 pp.

Nikuradse, J., 1933. Laws of flow in rough pipes. VDI Forschungsheft, p. 361.

Pawlowicz, R., Beardsley, B., Lentz, S., 2002. Classical tidal harmonic analysis including error estimates in MATLAB using T_TIDE. Computers \& Geosciences 28 (8), 929-937.

Raudkivi, A.J., 1988. The roughness height under waves. Journal of Hydraulic Research 26 (5), 569-583.

Rogers, W.E., Hwang, P.A., Wang, D.W., 2003. Investigation of wave growth and decay in the SWAN model: three regional scale applications. Journal of Physical Oceanography 33 (2), 366-389.

Rogers, E., Lin, Y., Mitchell, K., Wu, W.-S., Ferrier, B., Gayno, G., Pondeca, M., Pyle, M. Wong, V., Ek, M., 2005. The NCEP north american mesoscale modeling system: final eta model/analysis changes and preliminary experiments using the WRFNMM. In: Proc. of the 21st Conference on Weather Analysis and Forecasting/ 17th Conference on Numerical Weather Prediction, American Meteorological Society, Boston, p. 4B.5.

Seifert, T., Fennel, W., Kuhrts, C., 2009. High resolution model studies of transport of sedimentary material in the south-western Baltic. Journal of Marine Systems 75, 382-396.

Shchepetkin, A.F., McWilliams, J.C., 2005. The regional oceanic modeling system (ROMS): a split-explicit, free-surface, topography-following-coordinate oceanic model. Ocean Modelling 9 (4), 347-404.

Shearman, R.K., Lentz, S.J., 2003. Observations of tidal variability on the New England shelf. Journal of Geophysical Research 109, C06010. doi:10.1029/ 2003JC001972.

Sherwood, C.R., Lacy, J.R., Voulgaris, G., 2006. Shear velocity estimates on the inner shelf off Grays Harbor, Washington, USA. Continental Shelf Research 26, 19952018.
Signell, R.P., Beardsley, R.C., Graber, H.C., Capotondi, A., 1990. Effect of wave-current interaction on wind-driven circulation in narrow, shallow embayments. Journal of Geophysical Research 95 (C6), 9671-9678.

Soulsby, R.L., 1997. Dynamics of Marine Sands. Thomas Telford, London. 249 pp.

Soulsby, R.L., Whitehouse, R.J.S., 2005. Prediction of ripple properties in shelf seas. Technical Report 154, HR, Llingford, 97 pp.

Taylor, K.E., 2001. Summarizing multiple aspects of model performance in a single diagram. Journal of Geophysical Research 106. doi:10.1029/2000JD900719.

Tolman, H.L., 1999. User Manual and System Documentation of WAVEWATCH-III version 1.18, NOAA/NWS OMB Contribution No. 166, 110 pp.

Traykovski, P., 2007. Observations of wave orbital scale ripples and a nonequilibrium time-dependent model. Journal of Geophysical Research 112 , 06026.

Trowbridge, J.H., 1998. On a technique for measurement of turbulent shear stress in the presence of surface waves. Journal of Physical Oceanography 15 (1), 298306.

Trowbridge, J., Elgar, S., 2001. Turbulence measurements in the surf zone. Journal of Physical Oceanography 31 (8), 2403-2417.

Uchiyama, Y., McWilliams, J.C., Restrepo, J.M., 2009. Wave-current interaction in nearshore shear instability analyzed with a vortex force formalism. Journal of Geophysical Research 114, C06021. doi:10.1029/2008JC005135.

Umlauf, L., Burchard, H., 2003. A generic length-scale equation for geophysical turbulence models. Journal of Marine Research 61 (2), 235-265.

Warner, J.C., Sherwood, C.R., Arango, H.G., Signell, R.P., 2005. Performance of four turbulence closure models implemented using a generic length scale method. Ocean Modelling 8 (1-2), 81-113.

Warner, J.C., Sherwood, C.R., Signell, R.P., Harris, C.K., Arango, H.G., 2008. Development of a three-dimensional, regional, coupled wave, current, and sediment-transport model. Computers \& Geosciences 34 (10), 1284-1306.

Wessel, P., Smith, W.H.F., 1998. New, improved version of Generic Mapping Tools released. EOS Transactions of the American Geophysical Union 79 (47), 579.

Wiberg, P.L., Harris, C.K., 1994. Ripple geometry in wave-dominated environments. Journal of Geophysical Research 99 (C1), 775-789.

Wiberg, P.L., Rubin, D.M., 1989. Bed roughness produced by saltating sediment. Journal of Geophysical Research 94 (C4), 5011-5016.

Wiberg, P.L., Sherwood, C.R., 2008. Calculating wave-generated bottom orbital velocities from surface-wave parameters. Computers \& Geosciences 34 (10), 1243-1262.

Wilkin, J.L., 2006. The summertime heat budget and circulation of southeast New England shelf waters. Journal of Physical Oceanography 36 (11), 1997-2011. 